\title{
EDITORIAL
}

\section{LA UNPHU Y EL AGRO}

La Universidad Nacional "Pedro Henríquez Ureña", desde su fundación, se ha caracterizado por dos hechos fundamentales que han sido su sempiterna preocupación frente a la calidad de su enseñanza y el compromiso contraido con la comunidad donde nació y ha medrado. Primero enfatizar las humanidades, como un factor de enriquecimiento de la personalidad humana, y volcarse hacia el agro, hacia esa gran madraza de la vida donde descansa el porvenir econámico de la patria.

Ante el estragante espectáculo del éxodo de la gente del campo hacia la ciudad, el abandono de tierras ávidas del surco pródigo y la mano amiga así como el generoso sudor, la UNPHU, a través de la Hacienda Nigua, que forma parte de su patrimonio docente ha venido desarrollando una labor sin precedentes, dominando aquella tierra inculta, rodeada de fuerzas hostiles, y que crece como un oasis de abundancia en el desierto pedregoso de los ámbitos aledaños. En aquella tierra antes inhóspita deberá surgir, al impulso de la UNPHU, la primera Universidad agraria del país.

Todo el potencial económico de la República Dominicana, no nos cansaremos de repetirlo, descansa sobre el agro.

El Di. Jaime A. Viñas Román, nuestro Rector, ha escrito: "Del valor total de las exportaciones, las agricolas representan un elevado porcentaje mayor constituyendose asi en factor clave para la obtención de divisas que se utilizan para la importación de los bienes necesa- 
rios en el proceso de industrialización". ("Temas de interés nacional "Ed. UNPHU, Sto. Dgo. 1983).

De modo que es prioritaria la solución de este problema de $\tan$ vitales dimensiones. Ralp $H$. Allee ha dicho: "No hay países subdesarrollados sino paises con instituciones subdesarrolladas." Pero tampoco hay tierras malas, las tierras tienen el valor de los hombres que la trabajan. Los israelitas ha: hecho fértil el yermo y productivo el desierto, y los holandeses, en la pertinacia de su sobrevivencia, lograron robarle espacio al mar.

Junto con la agricultura fomentamos, complemento imprescindible, la pecuaria, otro de los renglones vitales en paises poco industrializados como el nuestro.

El Dr. Viñas Román insiste con ostensible vehemencia: "Es, por tanto, fácil de entender que el progreso dominicano está indisolublemente unido al desarrollo de su sector agropecuario y que el mejoramiento de las condiciones de vida y de la capacidad adquisitva de la población rural constituyen la más sólida base de una ampliación sustancial en la demanda de artículos manufacturados capaces de estimular la producción industrial" (opus cit.)

En una ocasión el Presidente de la República, Dr. Salvador Jorge Blanco, externó la idea feliz de que los servicios de investigación, extensión y capacitación del sector agropecuario oficial deberían estar a cargo de las universidades. Las autoridades de la UNPHU acogieron con gran entusiasmo esta idea presidencial convencidas como están de la gran verdad que encierra:

10. Por la proximidad de científicos disponibles para consulta y posible cooperación en proyectos de investigaciones.

20. Las facilidades, para el personal más joven, de recibir adiestramiento a nivel de post grado y de tener accesos a equipo adicional y facilidades de bibliotecas.

3o. La seguridad de que no habrá interferencia en las designaciones de investigadores por parte de políti$\cos$, y quedarán fuera la influencia de funcionarios públicos $y$ otros.

4o. El proceso educativo que realizan las universidades se beneficiaría notablemente, debido a la posibilidad de asignar docencia a tiempo parcial a los investigadores, contribuyendo as 1 con sus experiencias a la investigación actualizada y al adiestramiento de los 
futuros profesionales agropecuario.

¿De qué manera ha contribuido la UNPHU a la realización de estos programas?

- Con la venta de toretes (junto con la Secretaría de Estado de Agricultura) de alta calidad a medianos y pequeños ganaderos del país.

- Los programas de reforestación de las márgenes del río Nizao, como parte del desarrollo de su Recinto agropecuario de la Hacienda Nigua, en colaboración con estudiantes de las escuelas de la comunidad de Juan Barón (arbolitos tiernos de samán, eucalipto, acacia amarilla, flamboyán y corazón de paloma).

-El proyecto, en marcha, del Centro Nacional de Pesca, en Casa Najayo.

- Cursos de post grado para profesionales agrícolas, donde se impartan las siguientes disciplinas: silvicultura, extensión forestal, ecología,economía forestal etc., y los cuales tienen los siguientes objetivos básicos:

a) Formar un profesional a nivel de post grado adecuado a nuestros graves problemas forestales;

b) Fortalecer la enseñanza, investigación y desarrollo de los programas forestales nacionales;

c) La creación de un Plan Piloto de Desarrollo Forestal en el Recinto Agropecuario de la Hacienda Nigua;

d) La integración de la comunidad a los programas del Desarrollo Forestal.

- Se ha mejorado las ganadería a través del Banco de Semen y se han seleccionado ejemplares para el servicio de la comunidad. En febrero de 1984, la UNPHU envió a la finca "Peligro", propiedad de la Gulf and Western American Corp. cuatro toros de las razas Holstein pardo suiza y Charolais destinados al mejoramiento del ganado de aquella region. En esta finca los ejemplares pecuarios de la más alta calidad en su clase, son sometidos al proceso de extracción del semen, que es procesado por técnicos de la Gulf y se pone a la disposición de los ganaderos de la zona, a través del Programa de Inseminación Artificial (P/A) de la Dirección General de Ganadería de la UNPHU.

Recuerdese que en visita realizada a nuestra Universidad por directivos de la American Brahman Breeders Asociation, su presidente, señor Raymond Long expresó textualmente, ante lo que pudo observar 
en el Centro de Reproducción Ganadera UNPHU, que era "el mejor ganado Brahman que habla visto en su vida" y el Sr. Wendel Schronk, Vice-Presidente Ejecutivo, aseveró que "no existía una Universidad en los Estados Unidos con un hato de la calidad del que posee la UNPHU y que consideraba que era un prestigio y orgullo para el país tener un rebaño de estas condiciones."

-El plan de reforestación y siembra de árboles frutales y maderables en las siguientes sesiones aledañas a su Recinto agropecuario: Playa de Najayo, Carlos Pinto, La Cabirma, Mira Cielo, Entrada de Dios, Tierra Adentro, Dios dirá, Hato Viejo, La Canela, Boca de $\mathrm{Ni}$ gua, Loma de Boca de Nigua y Cambelén. Entre el 18 de noviembre de 1983 y el 1o. de Febrero de 1984 se sembraron: 17,769 cocoteros y 3,618 frutales que incluyen: cajuil, buen pan, guanábana, jagua, guayaba, mangos y zapote. Este programa continúa sin interrupción.

- Se han adquirido nuevos ejemplares vacunos, como el excelente toro Brahman Rojo 346, procedente del Rancho Koontz, en Texas, Estados Unidos, en colaboración con connotados ganaderos del país.

- La firma de un acuerdo con la Secretaría de Estado y Agricultura y el Fondo Especial para el Desarrollo Agropecuario (FEDA), con el objeto de desarrollar y poner en marcha los mecanismos que jerarquicen las actividades del Centro de Reproducción Ganadera y el Laboratorio de Procesamiento de semen congelado de la UNPHU. El objetivo de este convenio (según consta en el texto), es mejorar la ganadería del país con la producción de toretes de las razas lecheras Holstein y Pardo suiza, y de las de carne Brahman, Santa Gertrudis y Charolais.

Culminación de todos estos asertos es el acontecimiento de que fue sede la Universidad Nacional Pedro Henriquez Ureña (UNPHU) junto con la Secretaría de Estado de Agricultura (SEA), del 19 al 26 de agosto del presente año, esto es la celebración del 3er. Congreso Latinoamericano de Fitopatología y el $1 \mathrm{er}$. Congreso de la Sociedad Fitosanitaria Dominicana, bajo la experta conducción del Ing. Pedro María Germán Vásquez, Encargado de Programas de Investigación Agropecuaria de la UNPHU, que culminaron en un rotundo éxito. 